\title{
A CASA DOS SUASSUNA: REDE DE SOCIABILIDADES NA AMÉRICA E EM PORTUGAL
}

\author{
THE SUASSUNA HOUSE: A NETWORK OF SOCIABILITY IN \\ AMERICA AND PORTUGAL
}

Breno Gontijo Andrade ${ }^{1}$

\begin{abstract}
RESUMO: Em 1801 os irmãos Suassuna foram presos sob acusação de conspirarem contra a Coroa em um movimento que ficou conhecido como a Conspiração dos Suassuna. Houve interrogatório e acareações que serviram como fonte base para mapear parte das redes de sociabilidade dos Suassuna no Norte da América portuguesa. As fontes permitiram saber quem os visitava, com qual frequência, a quais grupos sociais pertenciam, sobre o que falavam e o que liam. Embora os irmãos fossem libertados posteriormente sob alegação de poucas provas, as fontes demonstraram que parte das acusações, de que falavam sobre ideias revolucionárias, era verdade. Outras fontes ajudaram a mapear as redes de sociabilidades dos Suassuna que se estendiam até Portugal. Em 1817 os Suassuna participaram da Revolução que se originou em Pernambuco e buscava a independência sob uma República.
\end{abstract}

PALAVRAS-CHAVE: Conspiração dos Suassuna, Revolução de 1817, Revolução Pernambucana, Redes de Sociabilidades, Livros.

ABSTRACT: In 1801 the Suassuna brothers were arrested on charges of conspiring against the Crown in a movement that became known as the Suassuna Conspiracy. There were interrogations and confrontations that served as a base source for mapping part of the Suassuna sociability networks in Northern Portuguese America. The sources made it possible to know who visited them, how often, which social groups they belonged to, what they talked about and what they read. Although the brothers were later released on the basis of little evidence, the sources demonstrated that part of the charges, that they spoke about revolutionary ideas, were true. Other sources helped to map the Suassuna social networks that extended to Portugal. In 1817 the Suassuna

\footnotetext{
* Pesquisa decorrente de estudos sobre a História do Livro e da Leitura, orientada pelo professor Luiz Carlos Villalta, desenvolvida no departamento de pós graduação em História da UFMG, com financiamento da FAPEMIG

${ }^{1}$ Professor da Universidade Federal de Minas Gerais - UFMG. brenohistoria@ gmail.com https://orcid.org/0000-0001-8820-6027
} 
participated in the Revolution that originated in Pernambuco and sought independence under a Republic.

KEYWORDS: Conspiracy of the Suassuna, Revolution of 1817, Revolution of Pernambuco, Social Networks, Books.

\section{Introdução}

Para o Norte da América portuguesa, no final do século XVIII, será que é possível dizer que surgiu uma esfera pública política que debatia sobre os acontecimentos da época tais como a independência das Treze Colônias ou a Revolução Francesa e seus desdobramentos? Se havia um amplo debate, o que era e quem discutia? Qual a relevância dessas discussões para sociedade da época? Talvez algumas dessas perguntas possam ser esclarecidas ao observar alguns documentos da época, como cartas, devassas, testemunhos. Antes desses documentos serem explorados faz-se necessário definir o que se entende por esfera pública política.

Jürgen HABERMAS pensa o conceito para o contexto europeu do século XVII e define esfera pública política como força que intermedia, através da opinião pública o Estado e as necessidades da sociedade (HABERMAS, 1984, p. 46). Na Europa, os salões e cafés seriam instituições da esfera pública, pois eram locais centrais de uma crítica inicialmente literária e, depois, também política (HABERMAS, 1984, p. 48). Na esfera pública haveria ainda a prática do segredo, uma vez que o seu público, mesmo enquanto público, ainda continua[va] obrigado a ser interno. Dessa forma, também seriam instituições da esfera pública as sociedades secretas, tais como academias e a maçonaria. Ainda que os salões, cafés, academias e maçonaria diferenciem-se entre si no tamanho e na composição de seu público, no estilo de seu comportamento, no clima de raciocínio, todos tendem a organizar a discussão permanente entre pessoas privadas (HABERMAS, 1984, p. 51).

$\mathrm{Na}$ esfera pública política, observam-se ainda três outras características: 1) a exigência de uma sociabilidade que pressupõe certa igualdade de status entre os seus participantes, mas que também, por muitas vezes, deixa de considerá-la; 2) a discussão que não poupa nenhum setor do questionamento, 
uma vez que o uso da razão deveria ser exercido sem limites e sem submissão à autoridade, como bem defendia Immanuel Kant; 3) o não fechamento do público em suas discussões, por mais exclusivo que ele pudesse ser, todos devem poder participar. Um grupo de interlocutores não se colocaria como equivalente ao grande público, mas como o seu porta-voz (HABERMAS, 1984, p. 53).

Roger CHARTIER, dialogando com Jürgen HABERMAS, define a esfera pública política em outros termos. Toma-a também como "um espaço para discussão e intercâmbio distante do controle do Estado e crítica dos atos ou do fundamento do poder estatal", onde pessoas privadas faziam uso público da razão (CHARTIER, 2009, p. 49). Dessa forma, os frequentadores das instituições da esfera pública, seriam mais ou menos iguais, a nível social e/ou cultural, na medida em que as distinções de ordens e estados eram relativamente reduzidas ou mesmo ignoradas.

Na América portuguesa, porém, essa restrição deve ser sopesada, pois não se pode esquecer da existência de intensa contiguidade entre senhores e escravos, por exemplo. Na Bahia, era possível ver "um criado conversando com seus patrões em termos mais igualitários e amigáveis, desafiando suas ordens e desrespeitando-as se elas contrariassem sua melhor opinião" (LINDLEY, 1805, p. 69). Nas instituições da esfera pública, o público tornava-se um tribunal, uma comunidade crítica, reunindo, debatendo e divulgando suas opiniões em salões, cafés, clubes e periódicos (CHARTIER, 2009, p. 52). Nesse caso, o público, pensado pouco antes da Revolução Francesa, não seria composto pelo povo, cuja opinião é apaixonada e oscilante, mas por aqueles que soubessem ler e produzir material escrito (CHARTIER, 2009, p. 72).

No início do século XIX, pode-se afirmar que havia certas discussões entre os grupos mais abastados, no Norte da América portuguesa, principalmente em Pernambuco. Participavam delas senhores de engenho, padres, negociantes, funcionários do governo real, militares de alta patente, homens que ocupavam posições de proeminência na sociedade pernambucana. 
Debatiam ideias, contavam as novidades que traziam as gazetas vindas do Reino, comentavam suas leituras, compartilhavam expectativas, dividiam suposições. Havia espaços onde se debatia, onde pessoas privadas faziam o uso público da razão, onde as distinções de nascimento eram diminuídas, havendo, como na Europa, distinções para aqueles que dominavam melhor a arte de argumentar. Entretanto, ainda que houvesse essa interação entre os pares, não podemos pensar o surgimento de uma esfera pública política no Norte, tal como é definida por Jürgen HABERMAS e Roger CHARTIER na França setecentista. Isso porque não há indícios da aparição dessa comunidade crítica nos moldes europeus, que se reunia, lia e debatia em cafés, salões, clubes, ao mesmo tempo em que escrevia em periódicos, com o intuito de difundir ideias e expô-las para a apreciação de um grande tribunal, a opinião pública.

Evidentemente, a inexistência de uma opinião pública aos moldes europeus não impossibilitava que houvesse particulares ou pequenos grupos críticos, que debatessem nesses espaços no Norte da América portuguesa, mas ainda longe de compor esse grande tribunal. $\mathrm{O}$ que se pode dizer sobre o Norte é que havia uma esfera pública política incipiente, que era clandestina e restrita, menos intensa que o grande tribunal existente na França, por exemplo.

No Norte da América portuguesa, as barreiras que impediam a constituição de uma comunidade crítica podem ter sido o iletramento elevado da região, a dificuldade de circulação de impressos imposta pela censura e a inexistência de tipografias na região, na medida em que tanto o acesso à leitura quanto à escrita de impressos ficava comprometido.

Aparentemente, a quantidade de iletrados era maior nas colônias portuguesas do que no Reino, que gozava de um comércio livreiro mais dinâmico e de permissões para o funcionamento de tipografias. Em Portugal, também se experimentava, nos finais do XVIII e início do XIX, a constituição de uma opinião pública, ainda que bastante anêmica. Luiz Carlos VILLALTA, por exemplo, ao analisar diversas investidas da Intendência Geral de Polícia, uma delas ocorrida em 1792, identifica que o intendente Diogo Inácio Pina Manique se preocupava com o que os súditos poderiam pensar, buscando agir 
sempre de modo que se satisfizesse o público. A noção de público de Pina Manique, segundo Luiz Carlos VILLALTA:

se confundia com a boa ordem e a justiça, e, ainda, parecia fundir-se com a satisfação, a correspondência de expectativa, de certa audiência. Esta opinião pública, contudo, não nos iludamos: naqueles tempos, no concreto, não corresponderia à avaliação majoritária entre os súditos, dispostos, no que se referia estritamente a isso, em situação de simetria. O próprio Intendente tinha clareza do contrário, que a justiça no Antigo Regime funcionava de forma assimétrica, ou seja, em consonância com a desigualdade dos vassalos, em termos de estado e de relações sócio-políticas (VILLALTA, 2011, p. 163).

Anos mais tarde, em abril de 1817, o redator de O Português, no início de seu segundo Memorial a D. João VI, publicado no número 36 do referido jornal, ameaçava, em linhas gerais, o soberano de recorrer a um tribunal maior, o tribunal supremo da opinião pública, caso seus agravos não fossem solucionados pelo próprio rei $(!)^{2}$. Esses episódios revelam que no Império Lusitano a opinião pública começava a se constituir.

Não havia de ser diferente entre os membros que compunham as elites do Norte da América portuguesa. Exerciam também a crítica fazendo o uso público da razão, porém com limitadíssimos efeitos, pois inexistia uma opinião pública no Norte nos moldes europeus.

As residências particulares como instituições da esfera pública: o caso da morada dos Suassuna

\footnotetext{
2 "Finalmente, já não conheço a Casa de Suplicação de Lisboa como último recurso dos meus agravos, mas ouso subi-los diretamente à presença de Vossa Majestade, e se aí não obtiver provimento, apelarei daí para um tribunal maior, mais augusto e de mais equidade do que são todos os reis do mundo, onde estes mesmos reis aparecem como réus e são julgados - apelarei para o Tribunal Supremo da Opinião Pública. Oh! Não deixe V. M. de atender às minhas súplicas nem consinta que elas se devolvam em última instância a esse tremendo tribunal para se aí julgar do seu merecimento. A Opinião Pública, senhor, não é como a Relação de Lisboa e outros tribunais de justiça que raras vezes condenam os juízes inferiores que tenham feito injustiça às partes. A Opinião Pública é um tribunal que exercita uma espécie de censura em todo o mundo. Ninguém aí aparece como réu que não sofra, sendo lhe provada a culpa, o condigno castigo do desprezo, infâmia ou execração universal" (MOURÃO, 1996, p. 201).
} 
$\mathrm{Na}$ Europa, uma instituição da esfera pública que tem suas raízes no século XVII, é o salão. Os salões eram locais para encontros, geralmente feitos em grandes residências. Eram frequentados pelos cortesãos e neles se apresentavam peças teatrais, havia recitação de poemas e de textos em prosa, danças, leituras em grupo e discussões sobre os temas do momento. As mulheres podiam frequentá-los; aliás, algumas delas eram as próprias anfitriãs. Ao longo do século XVIII, os salões sofreram algumas mudanças. Deixaram de ser tão frequentados. O grupo de anfitriões era composto majoritariamente por mulheres, e os convidados passaram a ser pessoas também de fora da corte, provocando certa mistura entre aristocratas a não aristocratas. Rousseau criticou a preponderância feminina nos salões, acusando esses espaços de terem se tornado cada vez mais frívolos e superficiais (OUTRAM, 1995, p. 91).

$\mathrm{Na}$ América portuguesa, no recorte espacial e temporal estudado, talvez houvesse algo parecido: nas residências, nas cidades e vilas, ou nos "matos" para usar um termo da época -, que serviam como ponto de encontro para os mais diversos debates. A maioria dos frequentadores, como se verá na documentação, era da elite da região, composta de homens notáveis pela abastança e/ou pela elevada cultura, além de muitos deles compartilharem de uma identidade aristocrática própria, que recuava ao século XVII (MELLO, 2008).

Muitas dessas elites locais cultivavam boas relações na corte, afinal, como afirma Nuno Gonçalves MONTEIRO, as reformas pombalinas, ao contrário das medidas adotadas pela Espanha, não excluíram do governo as elites de suas colônias. Na América Portuguesa, "não existia uma fratura geral, suscetível de ser alargada a todas as capitanias, entre as elites dominantes nascidas no reino e as que tinham nascido localmente". Havia um contato estreito entre Brasil e Portugal, com distinções menores do que entre a América Espanhola e Espanha (MONTEIRO, 2009, p. 56).

Nos seus encontros, as elites do Norte refletiam sobre temas correntes da época, recitação de poesia, leitura de algum livro importante, narração de algum caso jocoso, troca de experiências relativas às suas atividades, sempre 
acompanhados pelo entra e sai da escravaria, trazendo, em bandejas prateadas, gostosas iguarias, além de alguma bebida que servisse de refrigério e estimulante para debates acalorados. Não foi por acaso que uma das principais acusações contra os revolucionários de 1817 dizia que o projeto de Revolução foi tramado em casas, conciliábulos, ajuntamentos, assembleias, jantares, em uma palavra, em encontros entre particulares.

Após a Revolução de 1817, o advogado dos revolucionários, o senhor Aragão e Vasconcelos, elaborou a sua Defesa Geral. Nela expunha as principais acusações feitas contra os 317 acusados de participarem da Revolução de 1817, ao mesmo tempo em que tecia a defesa dos réus. Visando a minimizar a importância desses encontros em uma possível preparação da Revolução de 1817, dizia que o hábito dos homens se agruparem era bastante comum. Acrescentava que o ato de se encontrar em espaços de sociabilidades não era prova suficiente de que algumas pessoas estivessem planejando uma insurreição contra a Coroa Portuguesa. Dizia:

As assembleias e sociedades a que dão vários nomes conforme os pretextos, que se tomam para as adquirir, são frequentes em todas as cidades, ainda em vilas, e até mesmo em aldeias, e nunca foram proibidas, e nem suspeitas em algum Estado, porque se fazem publicamente e tem um fim útil qual é o alívio dos cuidados empregados nos negócios públicos e particulares, de que cada um está incumbido, cuja diversão é agradável, a comunicação de ideias, juízos e raciocínios, com o que muitos se instruem, a perfeição da moral que se vai adotando à proporção que cada um ouve em conversações exaltada a virtude e ludibriado o vício. Além disso, nelas se trataram negócios, casamentos, e outras muitas coisas interessantes que ninguém conclui mergulhado no seu gabinete, e por isso são mais úteis do que prejudiciais a qualquer Estado e nenhum estadista jamais as teve por suspeitosas (DH, vol. CVI, p. 81).

Independentemente do fato de a Revolução de 1817 ser tramada ou não em espaços de sociabilidade, o advogado evidencia que os encontros não só eram frequentes em Pernambuco, como em qualquer cidade, vila ou aldeia de qualquer país. Na verdade, eles faziam parte de um costume da época, o que não deveria surpreender ninguém, pois os encontros eram mais úteis do que 
prejudiciais aos Estados. Eram através deles que as pessoas divertiam-se, distraíam-se e gozavam de "alívio dos cuidados empregados nos negócios públicos e particulares". Além disso, o contato entre essas elites servia para instrução, pois havia "comunicação de ideias, juízos e raciocínios", que eram ouvidos por todos. É claro que a argumentação do advogado Aragão e Vasconcelos se pauta em defender os acusados, pois ele tenta diminuir o caráter pernicioso dessas reuniões, dizendo que elas até serviam para ludibriar o vício e elevar a virtude dos seus participantes. Reunidos, os homens tratavam de todos os assuntos, firmavam até amarrações familiares ${ }^{3}$.

Finaliza o advogado, que era óbvio que esses tipos de encontros aconteciam, pois nada se podia concluir de interessante no isolamento dos gabinetes. Fica claro que a intenção do advogado era ocultar um perigo evidente que esses encontros poderiam assumir, de ameaça ao Estado, pois consistiam verdadeiramente em uma esmaecida esfera pública política ${ }^{4}$.

No últimos anos do século XVIII e início do século XIX, uma dessas instituições da esfera pública de Pernambuco era a movimentada casa dos irmãos Cavalcanti de Albuquerque, também conhecidos como Suassuna. Eram eles abastados senhores de engenho que, inicialmente, buscavam por honrarias e distinções no Reino. O pai dos irmãos, por exemplo, Francisco Xavier

\footnotetext{
${ }^{3}$ As amarrações familiares fazem parte da base da política e do poder exercido nessa época, não só em Pernambuco, mas em todo o Norte da América portuguesa. Ainda faltam mais estudos sobre a importância dessas famílias na condução da Revolução de 1817 ou no seu desmantelamento. Serioja Rodrigues Cordeiro Mariano, professora da UFPB, em estudo pioneiro, dedicou o capítulo 2 de sua tese, intitulada Uma Revolução em Família: Poder Familiar e Política no Movimento de 1817, ao entendimento da importância dessas famílias no apoio à revolução de 1817, ocorrida na Paraíba. A família Albuquerque Maranhão, por exemplo, tinha ramificações que abarcavam o Rio Grande do Norte, Paraíba e Pernambuco. Outra família proeminente era a dos Carneiro da Cunha, também influentes na Paraíba e Pernambuco. Há também outras famílias tão importantes quanto as citadas, que não passam despercebidas da professora. Após a Revolução de 1817, segundo Serioja Mariano, algumas famílias valeram-se do seu poderio e influência para atenuar a pena de alguns parentes, ou mesmo livrá-los dos perigos da acusação. Para mais detalhes, ler (MARIANO, 2005).

${ }^{4}$ Maria Beatriz Nizza da SILVA, ao estudar esses encontros particulares no Rio de Janeiro, diz serem comuns as assembleias ou partidas noturnas em todas as casas onde existia algum par de pataca. Nessas reuniões, costumava-se passar o tempo em adivinhações, enigmas e jogos de salão. Em 1815, por exemplo, foi estabelecida uma sociedade de recreio, conhecida por Assembleia Portuguesa, cujo objetivo era reunir pessoas de boa educação e conduta, que pudessem adotar como passatempo os jogos de carteados, músicas e danças. A Assembleia Portuguesa ainda contaria com um gabinete de leitura, com gazetas portuguesas, estrangeiras e periódicos de ciências e artes (SILVA, 1977, p. 69).
} 
Cavalcanti de Albuquerque, antes de morrer tentou através de um pedido com quase trezentas páginas o foro de fidalgo cavaleiro. Mas o pedido fora recusado pela Mesa da Consciência e Ordens ${ }^{5}$. Os irmãos também buscaram por algumas distinções como logo veremos.

A residência dos Suassuna era movimentada e só é possível acompanhar essas visitas porque foi feita uma devassa em 1801, em virtude da suspeita de que os irmãos Suassuna conspiraram contra a monarquia portuguesa.

As autoridades reais pernambucanas ouviram cerca de 86 depoentes, incluindo neste grupo o próprio delator da conspiração, José da Fonseca Silva e Sampaio, e excluindo os acusados. Os depoentes, geralmente, respondiam a três perguntas: se tinham alguma amizade com os irmãos acusados, se sabiam quais eram as pessoas com quem os irmãos tratavam com maior familiaridade e, por fim, se suspeitavam ou haviam visto e ouvido os irmãos tratarem sobre "ideias de liberdade, mudanças de governo".

O assunto sobre "ideias de liberdade, mudanças de governo" chamava a atenção das autoridades porque as Treze Colônias há poucos anos conseguira sua emancipação da Grã-Bretanha e lá trataram de ideias de liberdade e mudanças de governo. Antes de irromper a Revolução Francesa também havia conversas sobre liberdade, sobre mudanças de governo. Através dessas perguntas feitas pelas autoridades reais, sobretudo, na primeira e segunda, é possível mapear as sociabilidades dos irmãos.

\begin{tabular}{|l|r|}
\hline \multicolumn{2}{|c|}{ Tabela I - Sociabilidades entre os depoentes e acusados } \\
\hline Dizia ter amizade com pelo menos um dos irmãos & 49 \\
\hline Dizia não ter nenhuma amizade com os irmãos & 37 \\
\hline Total de depoentes & 86 \\
\hline
\end{tabular}

Fonte: Documentos Históricos, vol. CX.

Conforme a Tabela I, dos 86 depoentes, segundo os autos da devassa, 49 revelaram ter amizade com pelo menos um dos irmãos, ou seja, eles afirmavam

${ }^{5}$ AHU_ACL_CU_015, Cx. 224\Doc. 15122. 
que tinham laços estreitos com os Suassuna. Por outro lado, os outros 37 depoentes eram categóricos ao afirmar que não tinham nenhum tipo de amizade com os irmãos, não frequentavam suas casas, mas que ou conheciam os irmãos, ou sabiam quem eram por ouvir falar. Esses dados revelam que as autoridades reais conseguiram identificar o círculo de amizade dos Suassuna, inquirindo tanto os amigos quanto os conhecidos. Para os magistrados, reunir tantos depoentes, que possivelmente frequentavam a casa dos irmãos, aumentaria as chances de se descobrir algum indício que comprovasse a organização de uma conspiração ${ }^{6}$.

Com base nesses dados, é possível identificar quem eram aqueles que mais frequentavam a casa dos irmãos e traçar o perfil social dos que mais se faziam presentes no convívio com os Suassuna. Para isso, coletei dados que satisfizessem uma das condições: ou depoentes que afirmaram, perante as autoridades reais, a amizade com os irmãos, ou pessoas que foram citadas como frequentadoras da residência dos irmãos por outras testemunhas.

Fonte: Documentos Históricos, vol. CX.

\footnotetext{
${ }^{6}$ Não me parece impossível que as próprias autoridades responsáveis pela investigação conhecessem os irmãos, principalmente pela notoriedade daquela família na região. Nos documentos sobre as primeiras conclusões da devassa, há o seguinte excerto, "[foram inquiridas] mais de oitenta testemunhas maiores de toda a exceção e da maior amizade com os denunciados" (DH, vol. CX, p. 23). Ademais, avento a hipótese de que um dos governadores interinos e também membro do corpo que inquiriu as testemunhas, o ouvidor José Joaquim Nabuco de Araújo (ascendente do afamado abolicionista Joaquim Nabuco), tinha um parente (talvez o irmão) que devia dinheiro aos irmãos Suassuna. Uma carta trocada entre os irmão Suassuna diz "Tenho muito poucas esperanças de cobrar do Nabuco, porque cá chegou outra letra protestada de um sujeito a quem ele caloteou, e recomendo-lhe que se o irmão lá não pagar proteste logo a letra (...)" (DH, vol. CX, p. 135).
} 


\begin{tabular}{|l|c|}
\hline \multicolumn{2}{|c|}{$\begin{array}{c}\text { Tabela II - Origem social dos frequentadores da casa dos Suassuna } \\
\text { citados entre o grupo dos depoentes }\end{array}$} \\
\hline "Vive de seu negócio" (Oficiais da Tropa de 2a e 3ª Linha) & $16(4)$ \\
\hline Tropa de 1 ${ }^{\mathrm{a}}$ Linha & 12 \\
\hline Clérigos/Professores & 10 \\
\hline Funcionários da Coroa & 7 \\
\hline Serviços Jurídicos & 4 \\
\hline Médicos/Cirurgião & 2 \\
\hline Guarda-Livros & 2 \\
\hline
\end{tabular}

Conforme se constata na Tabela II, o grupo mais numeroso é aquele designado pelas autoridades reais como de pessoas que "vivem de seu negócio"7. O número 4 está entre parênteses pelo fato de que apenas quatro componentes desse grupo eram designados simplesmente como vivendo do seu negócio. Os demais trazem cargos de distinção social, não remunerados, como membros das Milícias, as conhecidas tropas de $2^{\mathrm{a}}$ Linha - cerca de 12 membros - e das Ordenanças, isto é, as tropas de $3^{\mathrm{a}}$ Linha - apenas 3 membros. Na devassa, não há definição dos negócios desses homens, mas é de se esperar que eles ou eram grandes agricultores, ou negociantes, ou funcionários da administração portuguesa. Portanto, um terço dos frequentadores da casa dos irmãos era composto por homens distintos da região, com postos militares nas tropas não pagas ${ }^{8}$.

\footnotetext{
${ }^{7}$ Os números não devem ser tomados com extremada exatidão matemática, mas apenas como ponto de referência confiável, pelo fato de algumas testemunhas reportarem mais de uma ocupação, como por exemplo, ser oficial de segunda ou terceira linha e, ao mesmo tempo, funcionário da Coroa. As testemunhas que disseram ter mais de uma ocupação foram contadas duas vezes, uma para cada ofício (ao todo, apenas 4 testemunhas das 49 estão nessa situação, o que torna os números não tão precisos).

${ }^{8}$ Pertencem a esse grupo: José da Fonseca Silva e Sampaio (capitão do regimento de Milícias dos Nobres), Joaquim Bernardo Barata (ajudante - pago - do regimento de Milícias da freguesia do Cabo), Ângelo Vieira Miquelim (sargento-mor do regimento de Milícias de Olinda), Anastácio Clemente José (sargento-mor do regimento de Milícias de Rebelo), Francisco do Rego Ramos (tenente coronel de Milícias do regimento do Cabo), João Nepomuceno Paz (capitão do regimento de Milícias dos Nobres), José Bernardo de Lima e Albuquerque (ajudante do regimento de Milícias de Olinda), Luís José Soares (capitão do regimento de Milícias de Araújo), Manuel José Martins Ribeiro (capitão do regimento de Milícias de Olinda), André de Albuquerque Maranhão (capitão-mor das Ordenanças da Vila Flor e Vila de Ares da capitania do Rio Grande do Norte), Álvaro Barbalho Uchoa Cavalcante
} 
Em seguida aparece o grupo dos militares que viviam de seus ofícios, isto é, aqueles que compunham a tropa de $1^{\text {a }}$ Linha. Dos 49 depoentes que se disseram amigos dos irmãos, cerca de um quarto pertencia a esse grupo ${ }^{9}$.

Logo após, figuram os clérigos com 10 aparições ${ }^{10}$. Embora se constate que os oficiais de $1^{\mathrm{a}}, 2^{\mathrm{a}}$ e $3^{\mathrm{a}}$ Linha estão em maior número na frequência à morada dos Suassuna, eram os eclesiásticos os que se faziam mais presentes, isto é, eles são citados repetidamente por diferentes depoentes. Dos cinco nomes mais citados como frequentadores da casa dos irmãos, três eram de clérigos, sendo que o mais apontado era o padre Manuel do Loreto Bastos, mencionado 32 vezes por diferentes depoentes. Além do mais, se não considerarmos apenas o universo dos depoentes que frequentavam a casa dos irmãos, mas todos os nomes que foram mencionados na devassa ${ }^{11}$, o número de padres salta de 10 para 15 eclesiásticos.

$\mathrm{Na}$ quarta colocação, há os funcionários da administração portuguesa, com um total de 7 homens citados pelos demais depoentes. Todos esses dados revelam o perfil típico da elite colonial da América portuguesa, militares de $1^{\mathrm{a}}$

(capitão de Ordenanças), João Carneiro da Cunha (sargento-mor de Ordenanças de Olinda), Timóteo Luiz Bastos (vive de seu negócio), Gervásio Francisco Soares (vive de seu negócio), José Luiz dos Santos (vive de seu negócio) e Francisco Antônio de Souza (vive de seu negócio).

${ }^{9}$ Os oficiais militares que ao mesmo tempo foram depoentes e citados por outras testemunhas, organizados pela quantidade de aparições nos demais depoimentos, são: José Inácio Borges (porta-bandeira do regimento de Linha de Olinda), Duarte Guilherme Ferreira (tenente da tropa de Linha de Olinda), Manuel Silvestre da Fonseca Silva (alferes do regimento de Linha de Olinda), Francisco de Albuquerque e Melo (tenente do corpo de Artilharia), Jorge Eugênio de Loiro e Seilbay (brigadeiro chefe do regimento de Linha de Olinda), Francisco José da Costa Rocha e Mendonça (ajudante do corpo de Artilharia), João Roberto Pereira da Silva (coronel do regimento de Linha do Recife), João Vieira da Silva Cavalcante (ajudante de ordens), José de Barros Falcão (alferes do regimento de Linha do Recife), Amaro Francisco de Moura (cabo de esquadra do corpo de Artilharia), Domingos Francisco de Souza (cabo de esquadra do regimento de Linha de Olinda), Sebastião Marques das Virgens (capitão do regimento de Linha do Recife).

${ }^{10}$ Manuel do Loreto Bastos (religioso beneditino), Bento da Trindade (religioso agostinho descalço e professor), Ambrósio de Mirabelo (religioso capuchinho), José Joaquim de Santana Laboreiro (religioso de São Jerônimo e professor), João Agostinho (religioso capuchinho), João Nepomuceno da Silva (presbítero secular, capelão de São Francisco), Patrício Monteiro (presbítero secular), Miguel Nunes de Andrade (presbítero secular, capelão de São Francisco e professor), Angelo Maurício de Niza (religioso capuchinho) e Inácio Pinto de Almeida Castro (vigário da freguesia de Santo Amaro do Jaboatão).

${ }^{11}$ Há pessoas que foram mencionadas na devassa, mas que não prestaram testemunho. 
Linha, Milícias e Ordenanças, clérigos e funcionários reais ${ }^{12}$; em uma palavra, homens distintos da região frequentavam a casa dos Suassuna.

O restante é composto por pequenos grupos pouco representativos nessa contagem geral, como aqueles que se dedicavam aos serviços jurídicos, professores, médicos/cirurgiões e guarda-livros. Porém, da presença de representantes desses pequenos grupos conclui-se que a casa dos irmãos era também frequentada por homens de perfil social diferente daquele do que ali preponderava, isto é, também por pessoas que não exerciam cargos militares, eclesiásticos ou de funcionários da Coroa portuguesa.

\section{Tabela III - Origem social dos grupos que frequentaram a casa dos Suassuna, por quantidade de menções, entre todos os que foram mencionados nos depoimentos}

\begin{tabular}{|l|c|c|}
\hline \multicolumn{1}{|c|}{ Ocupação } & Absoluto & Relativo \\
\hline "Vive de seu negócio" (Oficiais da Tropa de 2a e 3 ${ }^{\mathrm{a}}$ Linha) & 55 & $18,70 \%$ \\
\hline Tropa de 1 ${ }^{\mathrm{a}}$ Linha & 68 & $22,30 \%$ \\
\hline Clérigos & 109 & $35,74 \%$ \\
\hline Funcionários da Coroa & 35 & $11,48 \%$ \\
\hline Serviços Jurídicos & 14 & $4,59 \%$ \\
\hline Médico/Cirurgião & 2 & $0,66 \%$ \\
\hline Guarda-Livros & 9 & $2,55 \%$ \\
\hline Desconhecidos & 12 & $3,93 \%$ \\
\hline Total & 304 & $100 \%$ \\
\hline
\end{tabular}

Fonte: Documentos Históricos, vol. CX.

Se nos basearmos na quantidade de nomes que são mencionados por todos os depoentes, chegaremos a um total de 304 menções $^{13}$. Os oficiais

\footnotetext{
${ }^{12}$ Os funcionários mencionados são: Manuel Caetano de Almeida de Albuquerque (escrivão da Provedoria de resíduos e ausentes e capelas), Antônio de Faria Brandão (provedor da Fazenda real da Paraíba do Norte), Francisco Xavier de Oliveira (ajudante do inquiridor da Ouvidoria), Estanislau Pereira de Oliveira (inquiridor da Ouvidoria), Francisco Joaquim Pereira de Carvalho (Escrivão dos órfãos), João Anastácio da Cunha Vale (primeiro oficial da secretaria da Junta da Fazenda de Pernambuco) e João Nepomuceno Paz (Tesoureiro dos Ausentes).

${ }^{13}$ Não se trata de nomes diferentes, mas de nomes que foram ditos por diferentes depoentes, podendo, vários deles, serem repetidos. Utilizei-me desses dados para tentar identificar quais
} 
militares da tropa de $1^{\mathrm{a}}$ Linha, ao todo, são mencionados 68 vezes $(22,30 \%)$, enquanto os militares de $2^{\mathrm{a}}$ e $3^{\mathrm{a}}$ Linha são mencionados 55 vezes $(18,70 \%)$ em diferentes depoimentos. Por sua vez, os clérigos, mesmo em número inferior aos militares, são mencionados 109 vezes $(35,74 \%)$. Os funcionários da Coroa portuguesa têm seus nomes mencionados 35 vezes $(11,48 \%)$ e, por fim, aqueles que viviam dos serviços jurídicos aparecem 14 vezes (4,59\%). Os números aqui utilizados evidenciam o perfil social preponderante entre os homens que cercavam os Suassuna e, através deles, pode-se concluir que uma quantidade considerável de súditos com postos militares nas tropas de $1^{\mathrm{a}}, 2^{\mathrm{a}}$ e $3^{\mathrm{a}}$ Linha visitavam os irmãos com alguma frequência, enquanto os clérigos representavam um grupo menor, como demonstra a Tabela II, mas que era, proporcionalmente, mais assíduo na residência dos Suassuna - como evidencia a Tabela III. Os funcionários da Coroa portuguesa também visitavam os irmãos, mas não eram tão presentes como os grupos supracitados.

Outro fator importante a se considerar é a disposição geográfica desses depoentes, amigos dos Suassuna, pelo Norte. Os Suassuna tinham amigos desde o Cabo de Santo Agostinho até o Rio Grande do Norte ${ }^{14}$. Porém, dentro do grupo dos amigos depoentes, a maioria habitava o Recife/Olinda, o grande centro, por assim dizer, do Norte da América portuguesa ${ }^{15}$. Desse modo, evidencia-se que os irmãos eram bem relacionados, pois cultivavam amizades com homens de destaque naquela sociedade, ao mesmo tempo em que se encontravam geograficamente dispersos, ou vivendo, ou transitando por todo o Norte. Ademais, deve ser lembrado que os irmãos pertenciam a uma família das mais tradicionais da região, o que os tornava ainda mais conhecidos e bem relacionados.

pessoas eram as mais citadas como frequentadoras, deduzindo que as mais frequentes eram também as mais próximas dos Suassuna. $\mathrm{O}$ número total de diferentes pessoas citadas como frequentadoras da casa dos irmãos é de 64 indivíduos.

${ }^{14}$ Mais à frente, será retomada a origem geográfica daqueles que tinham relações com os Suassuna e que, ao mesmo tempo, figuram na documentação. Um mapa foi feito a fim de facilitar a visualização dessas relações entre os Suassuna e os frequentadores de sua casa.

${ }^{15}$ A maior parte desses amigos, que diziam morar no Recife ou em Olinda, tinha funções em outras regiões. Acrescentei essas regiões no mapa, supondo que, embora muitos dos oficiais residissem no Recife/Olinda, exerciam influência nas localidades para as quais foram designados pela Coroa Real. 
Após identificar as origens sociais e a disposição geográfica daqueles que frequentavam a residência dos irmãos, cabe agora saber o que a documentação diz sobre o que se conversava nos círculos íntimos dos Suassuna.

José da Fonseca Silva e Sampaio ${ }^{16}$, negociante e capitão do Regimento de Milícias dos Nobres, era amigo próximo dos Suassuna $^{17}$ e foi apontado por, pelo menos 24 depoentes, como assíduo frequentador da casa dos irmãos. Para se ter uma ideia de como Fonseca era presente na casa dos Suassuna, o nome dele figura na segunda colocação entre os mais citados nos depoimentos. Não se sabe o porquê, mas foi ele quem alertou as autoridades sobre a existência de uma conspiração supostamente liderada pelos Suassuna. Por ser publicamente um homem de convívio íntimo com os irmãos, as acusações de Fonseca talvez mereçam crédito; aliás, é bem provável que os inquiridores tenham confiado em sua acusação e a levado adiante pelo fato de ele conhecer muito bem os Suassuna e, até aquele momento, não ter nenhum grande conflito com os irmãos.

Em seu depoimento, Fonseca menciona duas visitas que ele havia feito a Francisco de Paula Cavalcanti de Albuquerque ${ }^{18}$ e descreve a conversa que tiveram. Segundo o depoimento de Fonseca, o Paula havia lido e comentado sobre algumas cartas que recebera do irmão, que, na ocasião, estava em Portugal. A leitura e as conversas aconteceram na própria casa do Paula, no dia 9 de maio de 1801, pelas dez horas e meia da noite e também no dia 11 de maio de 1801, pelas nove da manhã (DH, vol. CX, p. 20).

A primeira carta informava sobre as pretensões pessoais do irmão em Portugal e dava notícias políticas da Europa, especulando que a Espanha atacaria Portugal $^{19}$. Por isso, segundo a mesma carta, os irmãos e aqueles que "pudessem entrar em nossos projetos" não deveriam concorrer para os empréstimos que a Coroa Portuguesa faria naquela praça. A segunda carta tratava das mesmas "ideias revolucionárias" da primeira carta. No término de

\footnotetext{
${ }^{16}$ Doravante, Fonseca, como é chamado na documentação.

${ }^{17}$ Principalmente de José Francisco de Paula Cavalcanti de Albuquerque.

${ }^{18}$ Doravante, Paula, como é chamado na documentação.

${ }^{19} \mathrm{O}$ que logo se confirmou com o que hoje conhecemos como a Guerra das Laranjas.
} 
sua leitura, o Paula comentou que era preciso procurar a liberdade, ao que Fonseca respondeu que só no caso de convir toda a América. O Paula ainda insistiu: "nem havendo socorro de nação estrangeira como a França?"

As leituras das cartas e a conversa revelam o que se passava no interior da casa dos Suassuna. Ao que parece, Paula e Fonseca discutiam sobre notícias de acontecimentos políticos da Europa e que poderiam ter desdobramentos no Brasil. A Espanha, ao atacar Portugal, poderia derrotá-lo. No caso da perda de Portugal, talvez fosse o momento de procurar a liberdade, para que não caíssem nas mãos dos espanhóis, ou mesmo, deveriam procurar a liberdade pelo fato de Portugal passar por momentos desoladores, independentemente de o rei português ser derrotado ou não. Fonseca até menciona que o Paula, ao vê-lo em desordem sobre o tema que tratavam, disse-lhe que "isto era para o caso da perda de Portugal, ou de sua Alteza Real não vir para o Brasil, por se não sofrer jugo estrangeiro" (DH, vol. CX, p. 151). Porém, segundo Fonseca, ele mesmo foi rechaçou a ideia, dizendo que só apoiaria a busca pela liberdade, de que falava Paula, caso toda a América conviesse. Fonseca justifica essa sua resposta afirmando que somente disse esses termos ao Paula por reputar ser algo impossível, "por nunca se lembrar de semelhante coisa" (DH, vol. CX, p. 151). Paula ainda insistiu no assunto, perguntando se ele não apoiaria a busca por essa liberdade se fossem apoiados pela França. Entretanto, não se sabe a verdadeira resposta de Fonseca.

Ainda conversaram sobre outros assuntos, como questões pessoais do irmão do Paula, que estava em Portugal e sobre economia (no caso, de que não deveriam emprestar dinheiro para a Coroa Portuguesa que arriscava ser derrotada $)^{20}$. O Paula também parece ter conversado sobre ideias que Fonseca julgava serem "revolucionárias", mas, o delator não especifica quais eram essas

\footnotetext{
${ }^{20}$ A investigação feita pelas autoridades reais em 1801 encontrou uma carta que comprova, em parte, as acusações de Fonseca. Trata-se da carta enviada de José Francisco de Paula Cavalcanti de Albuquerque para o irmão Luiz Francisco de Paula Cavalcanti de Albuquerque, que, em um trecho, diz, "já recomendei o Paula que para o empréstimo que lá se vai abrir para a Fazenda Real, não dê nada, e o mesmo lhe peço" (DH, vol. CX, p. 134).
} 
ideias, alegando esquecimento, o que é no mínimo suspeito ${ }^{21}$. Dentre os demais depoentes, entre os que frequentavam ou não a casa dos irmãos, nenhum disse que eles tratavam de "ideias sediciosas e revolucionárias", ainda que ouvissem alguns rumores contrários. No entanto, eles fazem referências sobre outros assuntos discutidos.

Joaquim Dias de Mesquita, que se intitulava amigo dos irmãos e que foi citado seis vezes como frequentador da casa dos irmãos - ver Tabela IV, a seguir - dizia que os Suassuna eram homens de probidade e acreditava que eles não tinham

talento para ligarem duas ideias políticas, pois que as suas conversas segundo ele testemunha presenciou muitas vezes, eram somente relativas à cultura do açúcar ou o fabrico das aguardentes e as suas demandas (DH, vol. CX, p. 48).

Desconsiderando a possível tentativa da testemunha de proteger os irmãos tomando-os como incapazes de "ligarem duas ideias políticas"22, um dos assuntos discutidos foi a cultura do açúcar. É bem sabido que diversos senhores de engenho reuniam-se para tratar de diversos temas relativos à cana de açúcar, desde o seu plantio e manuseio até técnicas de produção, ou mesmo, o valor de mercado do produto. Henry Koster, nove anos após a suposta conspiração dos Suassuna, testemunhou esses encontros entre os senhores de engenho, que se reuniam, liam e debatiam entre si sobre diversos temas inclusive sobre o plantio de açúcar. Naturalmente, pois eram agricultores, e é bem possível que recebessem outros dos seus para a troca de experiências e para tratarem de outros assuntos, que fossem surgindo no vagar da conversação.

\footnotetext{
${ }^{21}$ Os inquiridores percebiam, com certo estranhamento, a dificuldade de Fonseca em especificar quais ideias revolucionárias eram tratadas com o Paula, como se nota no trecho a seguir, "E perguntado se mediando só dez dias da leitura da segunda carta ao dia em que deu a denúncia, como podia esquecer-se de tudo de sorte que nem ao menos em grosso podia mais referir-nos quanto ouviu ler" (DH, vol. CX, p. 174). Em outro trecho também lê-se, "E perguntado porque razão se lembra do conteúdo da primeira carta que lhe foi lida, sendo a primeira que se lhe leu a mais tempo, e se não lembra do conteúdo da segunda que se lhe leu a menos dias" (DH, vol. CX, p. 180).

${ }^{22}$ A possibilidade desse testemunho e dos demais marcarem-se por serem tendenciosos e exprimirem certa intenção, seja de proteger, seja de atingir os devassados, não deve ser esquecida. Uma vez que visitavam a casa dos irmãos e poderiam ser também acusados de comparsas dos irmãos, é possível que tendessem a não incriminá-los.
} 


\begin{tabular}{|c|c|c|}
\hline \multicolumn{3}{|c|}{$\begin{array}{l}\text { Tabela IV - Frequentadores da casa dos Suassuna por quantidade de citação em } \\
\text { diferentes depoimentos }\end{array}$} \\
\hline Nome & Ocupação & Qtde de citações \\
\hline Manoel do Loreto Bastos & Clérigo & 32 \\
\hline José da FONSECA Silva Sampaio & $\begin{array}{c}\text { Vive de seu negócio / } \\
\text { Milícias }\end{array}$ & 24 \\
\hline $\begin{array}{l}\text { Manuel Caetano de Almeida de } \\
\text { Albuquerque }\end{array}$ & Funcionário da Coroa & 23 \\
\hline Bento da Trindade & Clérigo/Professor & 18 \\
\hline Ambrósio de Mirabelo & Clérigo & 16 \\
\hline Joaquim Bernardo Barata & Milícias & 16 \\
\hline José Joaquim de Santana Laboreiro & Clérigo/Professor & 16 \\
\hline José Inácio Borges & Tropa de $1^{a}$ Linha & 13 \\
\hline Duarte Guilherme Ferreira & Tropa de $1^{\mathrm{a}}$ Linha & 12 \\
\hline Manuel Silvestre da Fonseca Silva & Tropa de $1^{a}$ Linha & 10 \\
\hline Antônio de Faria Brandão & Funcionário da Coroa & 6 \\
\hline Francisco de Albuquerque e Melo & Tropa de $1^{a}$ Linha & 6 \\
\hline Joaquim Coelho de Mesquita & Serviços Jurídicos & 6 \\
\hline Jorge Eugênio de Loiro e Seilbay & Tropa de $1^{a}$ Linha & 6 \\
\hline Manuel Antônio Ribeiro & Guarda-Livros & 6 \\
\hline Perfeito da Penha & Clérigo & 6 \\
\hline Plácido da Rocha Preto & Serviços Jurídicos & 5 \\
\hline Vicente Ferreira de Melo & Tropa de $1^{a}$ Linha & 5 \\
\hline
\end{tabular}

Fonte: Documentos Históricos, vol. CX.

Frei Ambrósio de Mirabelo, citado 16 vezes como assíduo na casa dos irmãos, revela que, entre eles, havia discussão sobre alguns livros. Lembra-se que, certa vez, quando estava "lendo um sermão do abade Fournai traduzido em italiano" relativo à fidelidade e outras funções que os vassalos deveriam prestar para o seu soberano, José Francisco entrou em seu quarto e lhe pediu para que 
traduzisse o livro para o português, "por gostar muito dele, e não saber o italiano" (DH, vol. CX, p. 72). O testemunho do clérigo parece ser tendencioso por tentar demonstrar que José Francisco apreciava uma obra que tratava sobre a fidelidade ao rei, o que poderia ajudar a provar sua inocência.

Entretanto, se for desconsiderado o assunto do livro supracitado, bem como a possível intencionalidade de frei Ambrósio de Mirabelo em proteger os acusados, ainda assim será perceptível que havia discussões, leituras, opiniões sobre alguns livros que abordavam a relação dos soberanos com seus vassalos, entre os acusados e os amigos que frequentavam a casa dos Suassuna.

Ângelo Vieira Miquelim (e algumas outras testemunhas) relata que "sempre presenciou que as conversações dos ditos eram sérias e honestas, sem que nelas jamais ouvira dizer mal de pessoa alguma" (DH, vol. CX, p. 76). Porém, o testemunho mais revelador sobre o que se conversava na casa dos Suassuna, além daquele feito por Fonseca, é o de frei Bento da Trindade.

O referido frei era religioso agostinho descalço, doutor e jubilado na Sagrada Teologia e dela professor no Seminário de Olinda. Foi citado 18 vezes, entre as testemunhas, como frequentador da casa dos irmãos. Perguntado pelos inquiridores sobre o envolvimento dos Suassuna com "ideias revolucionárias e sediciosas a favor da liberdade", respondeu que sobre isso nada sabia, que antes, pelo contrário:

ele testemunha sempre os reconheceu e reconhece fiéis vassalos, bons patriotas, e igualmente bons cristãos, dotados de muitas virtudes morais, e civis, diametralmente opostas ao espírito da sedição e por esta razão ele testemunha os supõe incapazes de semelhantes coisas, e se persuade ser caluniosa semelhante imputação, e inverossímil e incompatível com o seu caráter, gênio, conduta, mansidão e espírito religioso que sempre neles observou até por conversações que com eles tivera relativas a este mesmo objeto, em que sempre lhes conheceu um aborrecimento absoluto à inculcada liberdade francesa ${ }^{23}(\mathrm{DH}$, vol. CX, p. 101).

O significado da palavra "patriota", utilizada pelo frei Bento da Trindade, confunde-se com a ideia de "fiel vassalo" e com a de "bom cristão". Aliás,

\footnotetext{
${ }^{23}$ Os grifos são meus.
} 
essas características implicam uma à outra, sendo quase sinônimas e indissociáveis. Censurar a Revolução Francesa também seria um elemento que comprovaria esse pretenso "patriotismo" dos irmãos Suassuna. Novamente, deve-se lembrar da suposta intencionalidade do depoimento do frei, em proteger os irmãos. De acordo com a Tabela IV, o frei Bento da Trindade aparece na quarta colocação entre os que mais frequentavam a casa dos irmãos. Esse fato revela que os irmãos conversavam, sim, sobre as supracitadas "ideias revolucionárias e sediciosas a favor da liberdade", mas que, ao contrário do que eram acusados, não aprovavam a liberdade francesa.

Assim, tanto a acusação de Fonseca quanto o depoimento de frei Bento da Trindade comprovam que os Suassuna tratavam sobre "ideias revolucionárias e sediciosas a favor da liberdade", discordando apenas no que se refere à adesão às ideias: o primeiro, insinuando que abraçavam tais ideias, e o segundo, negando que compartilhassem daqueles pressupostos. O depoimento de frei Bento da Trindade ainda coloca em dúvida a veracidade do depoimento de outras testemunhas, que disseram desconhecer se os irmãos tratavam sobre "ideias revolucionárias", principalmente aquelas que mais visitavam os Suassuna, uma vez que tanto o $2^{\circ}$ maior frequentador dos Suassuna (Fonseca) quanto o $4^{\circ}$ (frei Bento da Trindade) concordavam que os irmãos tratavam sobre as mencionadas "ideias revolucionárias".

Dessa forma, a partir das fontes, conclui-se que, nos círculos íntimos dos Suassuna, falava-se pelo menos sobre notícias políticas da Europa e seus desdobramentos na América portuguesa, prováveis ideias sediciosas e revolucionárias, a cultura e o fabrico do açúcar, leituras e comentários sobre livros, opiniões sobre a liberdade francesa.

Voltando ao tema sobre a origem geográfica dos amigos e frequentadores da residência dos Suassuna, é bem provável que eles acionassem redes de sociabilidades e redes clientelares que abarcavam boa parte do Norte da América portuguesa. Muitos conhecidos não foram inquiridos pelas autoridades reais, mas apenas uma pequena amostra dos que frequentavam os círculos íntimos da residência dos irmãos. 
Anos depois, Henry Koster, em 1810, encontrou-se com um dos irmãos, José Francisco de Paula Cavalcanti de Albuquerque, governando a capitania do Rio Grande do Norte $^{24}$. A ele, entregou diversas "cartas de apresentação que trazia para o governador, de vários amigos seus de Pernambuco" (KOSTER, 1942, p. 110), o que demonstra que um dos irmãos ainda era estimado pelos seus de Pernambuco. Ao continuar seus percursos, Koster conseguiu algumas facilidades de José para atenuar os desconfortos de uma viagem tão longa. Ao chegar à Vila do Aracati, no Ceará, mandou o seu guia à frente para levar uma carta,

que recebera do governador do Rio Grande para o senhor José Fidelis Barroso, rico mercador e grande proprietário. À minha chegada soube que o guia entregara a carta, e o senhor Barroso dera as chaves de uma sua casa desocupada para que me hospedasse durante minha permanência (KOSTER, 1942, p. 160).

Ao se hospedar na casa, que, segundo os relatos do viajante, era bastante cômoda, apareceram três criados pretos do senhor Barroso, trazendo-lhe e aos seus acompanhantes bandejas com excelentes pratos, vinhos, doces, além de bacias de pratas e toalhas. Na manhã seguinte, para a surpresa do viajante, foi enviado um café matinal, e a criadagem procurou saber quais eram os desejos de Henry Koster. Após o desjejum, chegou Barroso para conhecer o viajante inglês, que logo se desculpou pelos inconvenientes que sua estadia estava a provocar. Eis o que Barroso respondeu, de acordo com o relato do viajante:

Disse-me não lhe ser possível modificar a forma de receberme, porque, afirmou, não pagaria suas dívidas para com o Governador do Rio Grande, a quem devia muitas obrigações, e decorrentemente, aproveitaria todas as ocasiões para

\footnotetext{
${ }^{24}$ Embora o cargo de governador fosse cobiçado, governar o Rio Grande do Norte parecia trazer menos prestígio. O Rio Grande do Norte contava com uma população bastante diminuta, tendo a sua capital uma população entre 600-700 habitantes, além de ser região pobre, fustigada por secas e carente de toda sorte de recursos, pelo seu posicionamento geográfico e por sua diminuta extensão. Além disso, segundo o mesmo viajante, o Rio Grande do Norte estava sujeito ao governador de Pernambuco, na ocasião, Caetano Pinto de Miranda Montenegro, ao contrário da Paraíba e do Ceará, que, na época, eram capitanias independentes (KOSTER, 1942, p. 109).
} 
expressar sua gratidão pelos meios que pudesse (KOSTER, 1942, p. 161) $)^{25}$.

Nesse relato, podemos perceber que as redes de sociabilidades e as redes clientelares dos irmãos alcançavam não só Pernambuco, Paraíba e Rio Grande do Norte, como os depoimentos de 1801 nos evidenciam, mas também o Ceará $^{26}$. Ao continuar a viagem rumo à Vila da Fortaleza, talvez por gratidão ao governador do Rio Grande do Norte, José Fidelis Barroso escreveu uma carta recomendando o inglês a um conhecido seu, o senhor Marcos Antônio Brício, que também o hospedaria (KOSTER, 1942, p. 167).

Em 1816, o irmão de José, Francisco de Paula Cavalcanti de Albuquerque, principal acusado nas devassas de 1801, acionaria essas mesmas redes de sociabilidades e redes clientelares que se ligavam à sua família. Pediu ao ouvidor de Olinda, Antônio Carlos Ribeiro de Andrada, que intercedesse junto ao seu irmão, José Bonifácio de Andrada e Silva - Intendente Geral das Minas e Metais e catedrático de Metalurgia na Universidade de Coimbra, na ocasião em Lisboa - em favor de seu filho, Luiz Francisco Cavalcanti de Albuquerque, recomendando-o aos lentes da Universidade, como revela a carta:

José. O Portador desta é o Ilustríssimo senhor Luís Francisco Cavalcanti de Albuquerque filho do Ilustríssimo Senhor Francisco de Paula Cavalcanti de Albuquerque, capitão-mor desta cidade, pessoa muito de minha estima, espero que lhe prestes todos os bons ofícios, recomenda-o aos Lentes da Universidade para onde vai. Estou certo, que ele se faz digno de tudo ${ }^{27}$.

O mesmo Francisco de Paula Cavalcanti de Albuquerque também se envolveu com a Revolução de 1817 e foi preso. Uma das acusações que pesavam contra ele era de "proclamar e escrever cartas aos parentes, e amigos

\footnotetext{
${ }^{25}$ As redes clientelares, a meu ver, sobrepõem- se às redes de sociabilidades, muitas vezes entrelaçando-se com elas. A relação entre José Fidelis Barroso e o Suassuna, bastante cortês, era também clientelar.

${ }^{26}$ O referido senhor José Fidelis Barroso não está arrolado entre aqueles que prestaram depoimento em 1801. Como era de se esperar, a rede de sociabilidades dos Suassuna era mais extensa do que as fontes revelam. A devassa de 1801 apresentou apenas uma pequena amostra daqueles que nutriam relações com os Suassuna.

${ }^{27}$ Essa carta se encontra na Biblioteca Nacional do Rio de Janeiro (BN-RJ, 49,3,7 nº 14).
} 
dos capitães-mores e coronéis para [participarem da revolução]" (DH, vol. CVI, p. 140), isto é, o Suassuna valeu-se de toda as suas redes de sociabilidades e redes clientelares, construídas ao longo dos anos, para atrair importantes homens para a Revolução, que, por sua vez, poderiam chamar outros conhecidos e seus dependentes.

Pelo menos desde o início do século XIX, os Suassuna cultivavam relações com importantes homens da corte. Em 1801, quando José Francisco de Paula Cavalcanti de Albuquerque se encontrava na corte, em Lisboa, comunicou em carta aos irmãos que, pouco antes de chegar, sua embarcação havia sido atacada por uma fragata francesa e que ele participou dos combates, tendo se destacado, o que o tornou conhecido e louvado "não só do povo como de D. Rodrigo ${ }^{28}$, a quem já [havia falado]" (DH, vol. CX, p. 165).

Em outra ocasião, ao tratar de seus assuntos pessoais, José relata, em carta aos irmãos, que D. Rodrigo já estava ao seu favor (DH, vol. CX, p. 139). Em Portugal, também teceu alguns contatos com D. Tomás José de Melo, exgovernador de Pernambuco entre os anos de 1787-1798, que, na primeira vez, o recebeu com frieza, mas, na segunda visita, após José lhe enviar um presente e ler uma carta de seu pai ao ex-governador, este o suportou melhor. O exgovernador ainda era bastante visitado por diversos pernambucanos que estavam na corte e iam pedir-lhe empréstimos, sendo por ele recebidos com toda a cautela, com receio de levar calote (DH, vol. CX, p. 165).

Todos esses episódios, citados até agora, mostram as redes de sociabilidades e clientelares dos Suassuna: eles eram conhecidos e bem relacionados, no Norte da América portuguesa, mas também em Portugal (ver Mapa I, abaixo).

Mesmo com todas essas redes, mesmo com o conhecimento de como funcionava as mercês e trocas de favores na corte, mesmo com a ocupação de postos de proeminência em uma sociedade de antigo regime, os Suassuna, envolveram-se na Revolução de 1817. A Revolução buscou a independência

\footnotetext{
${ }^{28}$ Trata-se de D. Rodrigo de Souza Coutinho, na ocasião era secretário de Estado da Marinha e Domínios Ultramarinos (1796-1801) e, posteriormente, presidente do Real Erário (1801-1803) e ministro da Guerra e Negócios Estrangeiros (1808-1812), na regência de D. João.
} 
sob a República. Dois dos irmãos juntos com os seus homens, escravos e suas redes participaram ativamente da Revolução ajudando a liderá-la. Outro irmão encontrava-se como governador de Moçambique, mas os seus irmãos e revolucionários trataram de enviar um navio para aquela capitania com pedidos de ajuda, mas não se sabe se o navio chegou ao seu destino.

Quando a Revolução de 1817 foi derrotada os irmãos e seus filhos que residiam em Pernambuco foram presos. Um dos filhos de Francisco foi morto e teve o seu corpo mutilado pelas tropas realistas. mais velho de Francisco foi morto e teve o seu corpo mutilado. Francisco ficou quatro anos presos e faleceu dias após ser libertado. José continuou como governador. Embora a família Suassuna tenha sofrido grande perda, ainda manteve suas redes de sociabilidade. Prova disso foi que, inicialmente, seus bens foram confiscados após sua participação na Revolução, mas foram restituídos posteriormente. 
Mapa I - Redes de Sociabilidades e Clientelares dos irmãos Suassuna entre 1801-1811 somente no norte da América portuguesa

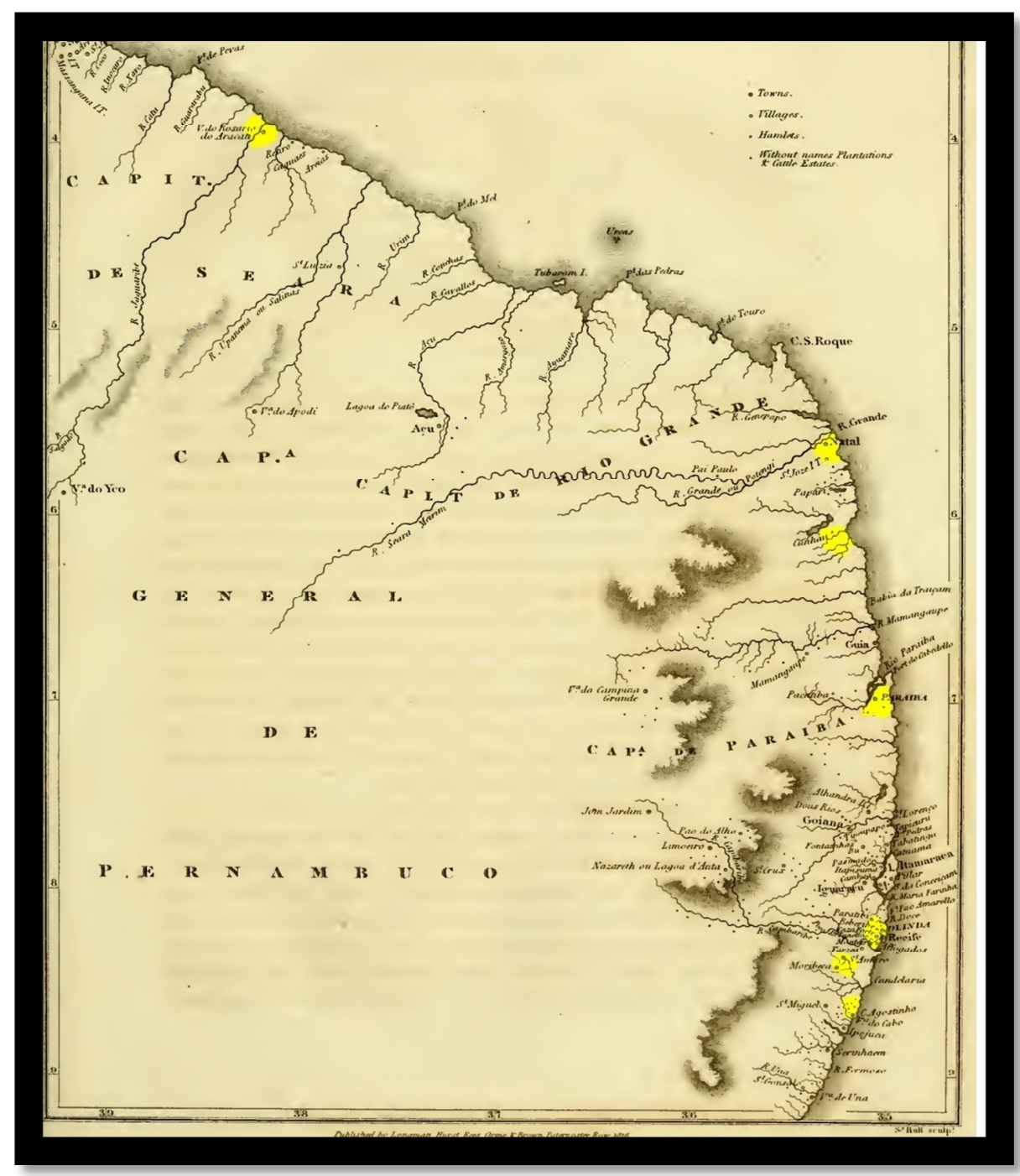

Legenda: Áreas que os irmãos tinham estreitos contatos comprovadas pela documentação

Fonte: KOSTER, Henry. Travels in Brazil. London: Printed for Longman, Hurst, Rees, Orme and Brown, 1816, p. 43. 


\section{Referências}

ANDRADE, Breno Gontijo. A Revolução de 1817: discursos, esquecimentos e lembranças. Divinópolis: Gulliver, 2021.

ANDRADE, Breno Gontijo. Duzentos Anos de 1817: caminhos historiográficos e algumas discussões sobre a Revolução Pernambucana. Opsis, Catalão, v. 17, n.1, p. 121-134, 2017.

ANDRADE, Breno Gontijo. A carta de amor extraviada ou sobre a conspiração epistolar desencontrada: indagações sobre a existência da suposta conspiração dos suassuna ocorrida no memorável ano de 1801. Saeculum, João Pessoa, 2013.

ANDRADE, Breno Gontijo. Brevíssima biografia do governador José Francisco de Paula Cavalcanti de Albuquerque. Temporalidades, Belo Horizonte, 2014.

ARQUIVO HISTÓRICO ULTRAMARINO (AHU). Requerimento coronel de Milícias da cidade de Olinda, Francisco Xavier Cavalcanti de Albuquerque, ao príncipe regente [D. João], pedindo foro de fidalgo cavaleiro, enviando para isso seus papéis de serviços militares, assim como os de seu pai, o mestre-decampo Luís Xavier Bernardo, e seus irmãos.

CHARTIER, Roger. Origens Culturais da Revolução Francesa. São Paulo: Editora Unesp, 2009.

DH - Documentos Históricos - A Revolução de 1817. Rio de Janeiro: Biblioteca Nacional, 1953-1955. 10 vol.

HABERMAS, Jürgen. Mudança Estrutural da Esfera Pública. Rio de Janeiro: Tempo Universitário, 1984.

HARTOG, François. Regimes de historicidade, presentismo e experiências do tempo. Belo Horizonte: Autêntica, 2014.

HARTOG, François. Tempo e história: como escrever a história da França hoje? História Social, Campinas (SP), n. 3, p. 127-154, 1996.

HARTOG, François. Crer em história. Belo Horizonte: Autêntica, 2017.

JENKINS, Keith. A história repensada. São Paulo: Ed. Contexto, 2001.

KOSTER, Henry. Viagens ao Nordeste do Brasil. Tradução e Notas de Luiz da Câmara Cascudo. São Paulo: Companhia Editora Nacional, 1942.

LE GOFF, Jacques. História e memória. Campinas: Ed. da Unicamp, 1992. 
LEITE, Glacyra Lazzari. Pernambuco 1817: estrutura e comportamentos sociais. Recife: Ed. Massangana, 1988.

LIMA, Manuel de Oliveira. D. João VI no Brasil. 3. ed. Rio de Janeiro: Topbooks, 1996.

LINDLEY, Thomas. Narrative of a Voyage to Brasil [sic], terminating in the seizure of a British Vessel, and the imprisonment of the author and the ship's crew, by the Portuguese... London: J. Johnson, St. Paul's Church-Yard, 1805.

LOPES, Machado Maximiano. Introdução à obra de Francisco Muniz Tavares. In: História da Revolução de Pernambuco em 1817. 3. ed. rev. e anot. por Oliveira Lima. Recife: Imprensa Industrial, 1917.

MARIANO, Serioja Rodrigues Cordeiro. Gente Opulenta e de Boa Linhagem: Família, Política e Relações de Poder na Paraíba (1817-1824). Recife: UFPE, 2005, pp. 62-139 [Tese de Doutorado em História].

MARTINS, Joaquim Dias. Os mártires pernambucanos victimas da liberdade nas duas revoluções ensaiadas em 1710 e 1817. Pernambuco: Typ. de F. G. de Lemos e Silva, 1853.

MELLO, Evaldo Cabral de. Rubro Veio - $O$ imaginário da restauração pernambucana. 3 Ed. São Paulo: Alameda, 2008.

MONTEIRO, Nuno Gonçalo. A Circulação das Elites no Império dos Braganças (1640-1808): algumas notas. Tempo, Niterói, 2009.

MOURÃO, Gonçalo de B. C. e Mello. A Revolução de 1817 e a História do Brasil. Belo Horizonte: Editora Itatiaia, 1996.

NEVES, Guilherme P. C. Pereira das. O Seminário de Olinda: Educação, Cultura Política nos Tempos Modernos. Niterói: Curso de Mestrado em História da UFF,1984 (Dissertação de Mestrado).

NEVES, Lúcia Maria Bastos P. Imagens de Napoleão Bonaparte na óptica dos impressos luso-brasileiros. In: DUTRA, Eliana de Freitas; MOLLIER, JeanYves. (Org.). Política, nação e edição - o lugar dos impressos na construção da vida política. São Paulo: Annablume, 2006. p. 579-594.

OUTRAM, Dorinda. The Enlightenment. Cambridge: Cambridge University Press, 1995. 
RIBEIRO, Mariana dos Santos. Construindo histórias e memórias: o IHGB e o IAGP em meio as celebrações do centenário do movimento pernambucano de 1817. Rio de Janeiro: PUC-Rio, 2011. (Tese de Doutorado.)

RODRIGUES, Thamara de Oliveira. Revolução de 1817 e as disputas historiográficas: Abreu e Lima e Francisco Adolfo Varnhagen. História e Cultura, Franca, v. 6, n. 1, p. 289-308, 2017.

SILVA, Andrée Mansuy Diniz. D. Rodrigo de Souza Coutinho, Comte de Linhares, 1755-1822: L'Homme d'État, 1796-1812. Paris: Centre Culturel Calouste Gulbenkian, v. 2, 2006.

SILVA, Maria Beatriz Nizza da. Cultura e Sociedade no Rio de Janeiro (1808-1821). São Paulo: Editora Nacional, 1977.

VILLALTA, Luiz Carlos. Impressão em Portugal: da política régia às publicações ilegais (c. 1750-1806). In: VERRI, G. M. W. (Org.). Memorat: Memória e cultura escrita na formação brasileira. Recife: Universi Federal de Pernambuco, 2011.

Recebido em: 21 de novembro de 2020

Aceito em: 13 de setembro de 2021 